\title{
Parametric Analysis on the Optimal Dimensions of Steel Sleeve in Swaging Type Anchorage for CFRP Tendon
}

\author{
Jae Yoon Kang, Jong Sup Park, Woo Tai Jung, Moon Seoung Kum \\ Structural Engineering Research Division, Korea Institute of Construction Technology, Goyang, Korea \\ Email: jykang@kict.re.kr, jspark1@kict.re.kr, woody@kict.re.kr, moonseoung@kict.re.kr
}

Received September 11, 2013; revised October 11, 2013; accepted October 18, 2013

Copyright (c) 2013 Jae Yoon Kang et al. This is an open access article distributed under the Creative Commons Attribution License, which permits unrestricted use, distribution, and reproduction in any medium, provided the original work is properly cited.

\begin{abstract}
This paper presents the parametric analysis conducted to derive the optimal dimensions of the steel sleeve necessary to secure the bond performance of the swaging type anchorage for CFRP tendon with diameter of 5 mm. To that goal, finite element analysis is performed on the parameters determining the dimensions of the sleeve like the thickness and inner diameters of the sleeve. The results show that a constant swaging pressure of about $450 \mathrm{MPa}$ on the mean is distributed in the sleeve when the thickness ratio of the stress relief zone to the effective swaging zone of the sleeve is larger than 1.1 and that the swaging pressure tends to reduce linearly as much as this thickness ratio becomes smaller than 1.1. The pressure varies within a range of about $30 \%$ according to the change in the inner diameter of the sleeve whereas varies within a range less than $10 \%$ according to the change in the inner diameter when the thickness ratio is larger than 1.1. Finally, the optimal dimensions of the steel tube sleeve enabling to secure an anchor force larger than the rupture strength of the CFRP tendon with diameter of $5 \mathrm{~mm}$ are determined based upon the results of the parametric analysis.
\end{abstract}

Keywords: CFRP Tendon; Prestressing; Swaging Type Anchorage; Swaging Sleeve

\section{Introduction}

Recently, research has been actively conducted on the repair and strengthening of structures using carbon fiber-reinforced polymer (CFRP) material. Research is also performed on the improvement of the strengthening efficiency of the conventional method simply bonding sheet or bar-shaped reinforcement on the surface of the member by embedding the reinforcement near the surface (NSM, Near Surface Mounted) or by introducing a jacking force simultaneously to the NSM $[1,2]$.

The methods adopted to anchor CFRP tendon can be classified into the wedge type, the bonded type and swaging type anchors. The wedge type anchorage generally adopted for anchoring PS steel wires or PS steel strands uses mechanical gearing through a wedge system which compresses the circumference of the tendon. The bonded type anchorage is a system which fills a steel pipe with expansive material or resin and secures its anchor performance by the bond force between the tendon and the filling material. The bonded type anchorage provokes lesser damage to the tendon than the wedge type and swaging type anchorages but presents the problem of becoming longer with larger sleeve since the anchor performance depends on the bond performance brought by the external shape and sheath of the tendon.

As shown in Figure 1, the swaging type or compression type anchor applies a pressure on the outer circumference of the steel pipe (sleeve) to increase the friction on the circumference of the tendon. Unlike the bonded type, this type of anchor does not require a curing period for the filling material and enables to shorten the length of the sleeve by more than 33\%. Jung et al. [3] evaluated the anchor performance of the swaging type anchor through an experimental study considering various parameters including the dimensions of the sleeve, and the eventual presence of insert. Their experimental results revealed that the anchor performance of the swaging type anchor varied according to the change in the swaging pressure itself depending on the inner and outer diameters of the sleeve. The authors reported also that the need was to mitigate the concentration of stress at the end of the sleeve by disposing a stress relief zone in order to prevent the rupture of the tendon at the end of the sleeve. These authors also reported that anchor performance reaching $94 \%$ of the rupture load of the tendon could be 


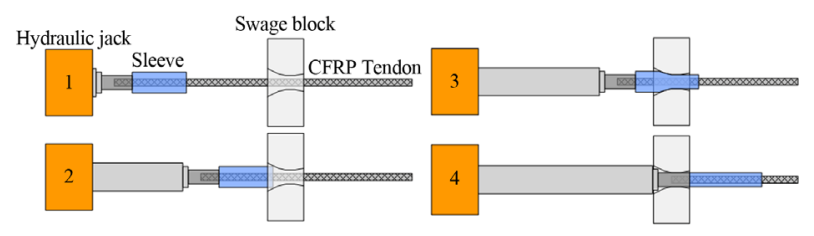

Figure 1. Compression scheme for compression type anchor [3].

obtained in the case of an inner diameter of the sleeve of $12 \mathrm{~mm}$ for a $\phi 9.5 \mathrm{~mm}$ tendon, that the optimal length of the taper was $40 \mathrm{~mm}$ and that a constant swaging pressure should be secured over a length longer than $80 \mathrm{~mm}$ to obtain sufficient swaging pressure for the anchor.

In addition, Jung et al. [3] examined the variation of stress according to the change in the inner diameter of the sleeve through finite element analysis as shown in Figure 2. This analysis enabled to state the existence of an adequate stress and of corresponding optimal dimensions of the sleeve to secure the tendon anchor performance.

This study focuses on the variation of swaging pressure according to the thickness of the sleeve for the swaging type anchor for CFRP bar with diameter of 5 $\mathrm{mm}$. The distribution characteristics of the swaging pressure are examined with respect to the thickness ratio of the stress relief zone to the effective swaging zone through finite element analysis. Finally, the optimal dimensions of the sleeve enabling to obtain the appropriate pressure are derived to secure the bond force of the CFRP tendon.

\section{Swaging Stress According to the Change in the Sleeve Thickness $t_{0}$}

\subsection{Description of Analysis Model}

The parametric analysis is performed using the finite element analysis software ABAQUS v.6.5. The steel pipe is modeled by means of planar axial symmetric model considering the symmetry of the pipe, and the dice is modeled as a rigid body. Loading is applied as shown in Figure 3 so as to push the rear face of the sleeve by displacement control up to $160 \mathrm{~mm}$ considering the fabrication method of the real swaging sleeve. This loading method enables to provoke swaging by gearing induced by friction with the CFRP tendon by generating the swaging deformation when penetrating the steel dice. At that time, the steel sleeve and the CFRP tendon are endowed with contact boundary conditions. In the contact boundary conditions, the coefficient of friction between the sleeve and the tendon is set conservatively to 0.15 referring to the value of 0.23 applied for the initial coefficient of friction between CFRP and the aluminum plate in a previous study [4] and considering the absence of studies dedicated to the coefficient of friction between

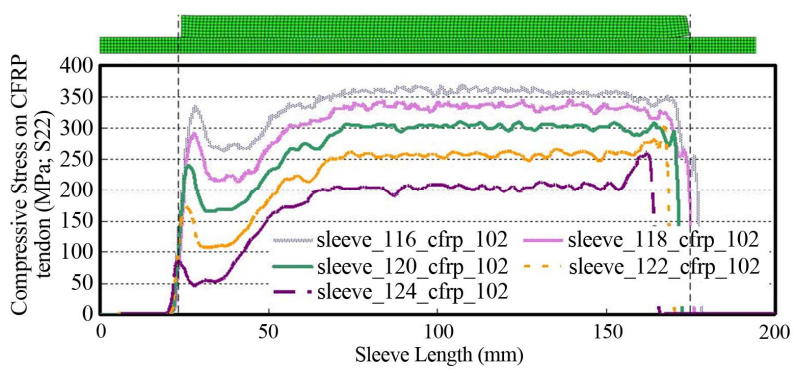

Figure 2. Swaging pressures developed in $\phi 9.5 \mathrm{~mm}$ CFRP tendon [3].

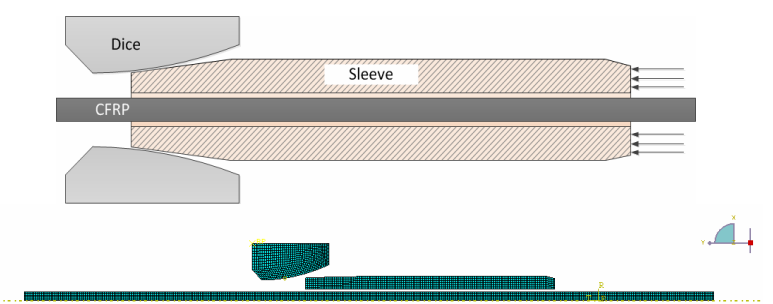

Figure 3. Loading method and analysis model.

the CFRP bar and the steel sleeve. Hard contact condition is adopted for the direction perpendicular to the contact surface. The boundary conditions are set so as to enable separation of the contact surface for the behavior in the perpendicular direction after contact. Note that the friction force between the dice and sleeve is neglected and attributed with frictionless conditions.

The material properties of the CFRP tendon and steel sleeve are listed in Table $\mathbf{1 .}$

\subsection{Range of Parameters}

Table 2 arranges the range of the parameters for the analysis and shows the analysis conditions for the evaluation of the variation in the swaging pressure with respect to the change in the thickness of the steel pipe sleeve. For the CFRP tendon with diameter of $5 \mathrm{~mm}$, the inner diameter of the sleeve, the length of the stress relief zone and the effective swaging zone in Figure $\mathbf{4}$ are respectively set to $6.5 \mathrm{~mm}, 40 \mathrm{~mm}$ and $80 \mathrm{~mm}$. The variation of the contact pressure developed inside the sleeve is evaluated by changing the thickness $t_{0}$ of the stress relief zone and the thickness $t$ of the effective swaging zone. Especially, focus is done on the variation of the swaging pressure according to the ratio of the thickness of the steel sleeve to the thickness of the taper $\left(t / t_{0}\right)$. The analysis intends to determine the thickness range enabling to minimize the concentration of stress occurring in the CFRP tendon and to obtain stable anchor effect.

In the analysis, the inner diameter of the dice is set with the value obtained by subtracting $\left(d_{1}-c\right)$ to the diameter $d_{2}$ so that the outer diameter of the sleeve penetrating the dice becomes fixed to $t_{0}$ and becomes bonded to the tendon. 


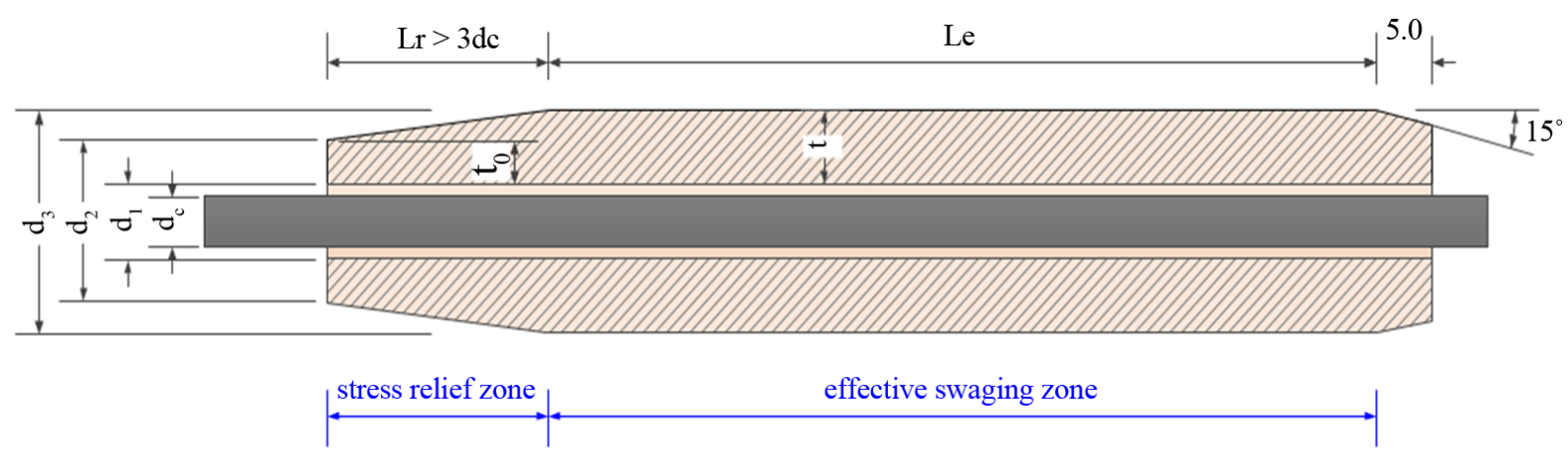

Figure 4. Definition of the dimensions of steel sleeve.

Table 1. Material properties of CFRP tendon and steel sleeve.

\begin{tabular}{cccccc}
\hline Member & Elastic modulus (MPa) & Yield strength (MPa) & Tensile strength (MPa) & Diameter (mm) & Cross sectional area (mm²) \\
\hline CFRP tendon $(\phi 5.0)$ & 165,000 & - & 3500 & 5.0 & 19.63 \\
Steel pipe sleeve & 200,000 & 400 & 569 & - & \\
\hline
\end{tabular}

Table 2. Range of parameters in analysis (variation of sleeve thickness).

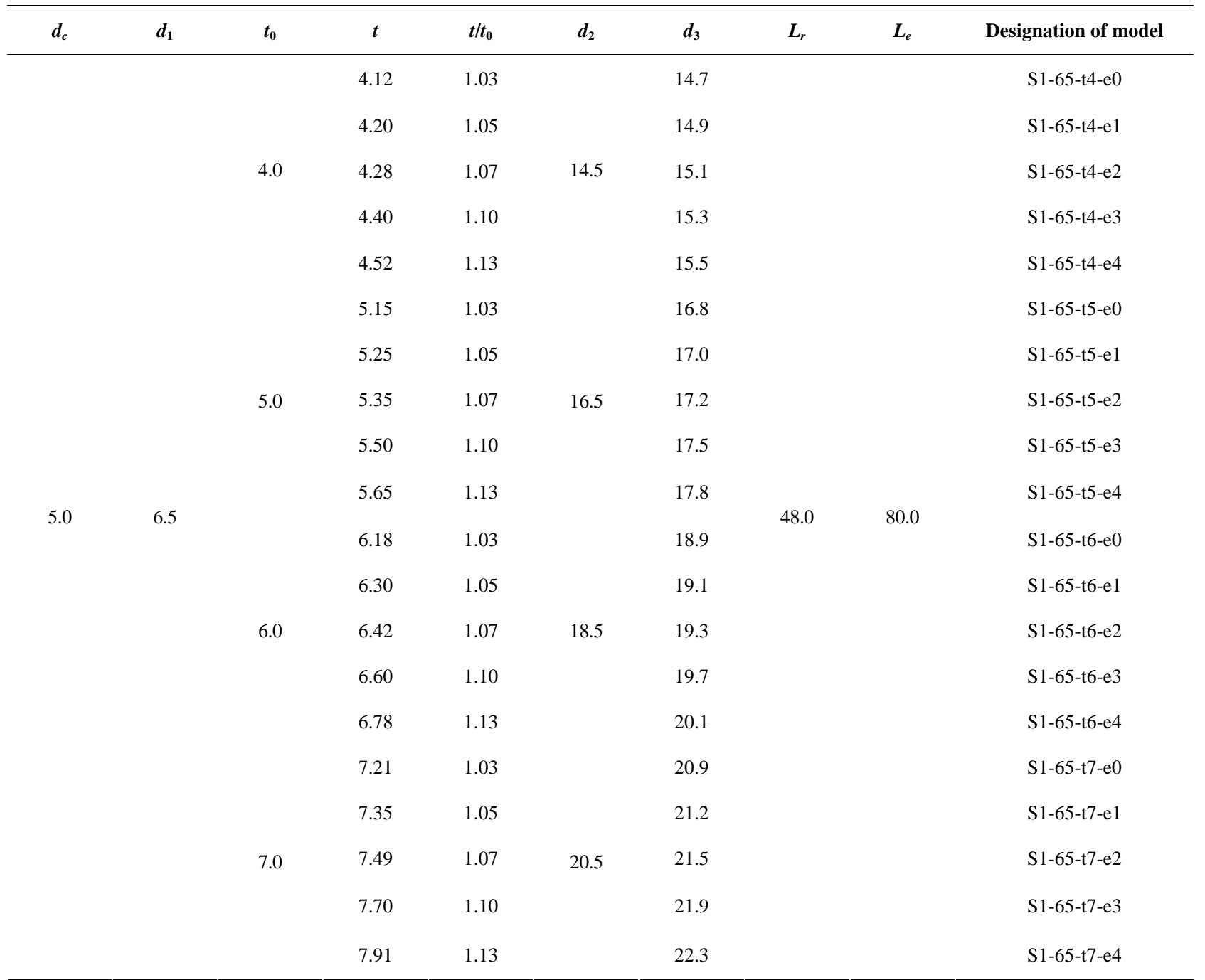




\subsection{Analysis Results}

Figure 5 shows the change of the pressure distribution in the cross section during the analysis process. It appears that the pressure distribution in the sleeve exhibits constant size after completion of swaging. This study also performs comparative analysis of the mean pressure occurring in the effective swaging zone of the steel sleeve for each analysis model. Figure 6 compares the distribution of the pressure in the sleeve according to the increase of the thickness $t$ of the effective swaging zone when the thickness of the steel pipe sleeve takes respective values of 4, 5, 6 and $7 \mathrm{~mm}$.

In Figure 6, the lowest pressure distribution is observed the thickness ratio $\left(t / t_{0}\right)$ has a very small value of 1.03. The variation in the pressure tends to increase according to the thickness ratio $\left(t / t_{0}\right)$ when the thickness $t_{0}$ becomes larger.

Figure 7 compares the mean pressure developed in the effective swaging zone according to the variation of the thickness $\left(t_{0}\right)$ of the sleeve and thickness ratio $\left(t / t_{0}\right)$. The variation of the pressure tends to widen according to the change in the thickness ratio for larger thickness of the sleeve.

Figure 8 compares the maximum pressure according to the change in the thickness ratio for each considered sleeve thickness $\left(t_{0}\right)$. It appears that the variation of the pressure is minimized for an arbitrary sleeve thickness when the thickness ratio is 1.10 . In such case, the mean pressure developed in the sleeve runs around $450 \mathrm{MPa}$. It can thus be expected that a constant swaging pressure can be achieved if the thickness of the effective swaging zone $t$ is decided to set the thickness ratio to 1.10 for an arbitrary sleeve thickness.

\section{Swaging Pressure According to the Change in the Sleeve Inner Diameter $\left(d_{1}\right)$ and Thickness Ratio $\left(t / t_{0}\right)$}

\subsection{Range of Parameters}

In order to investigate the swaging performance according to the variations of the inner diameter and thickness of the sleeve, the change in pressure is examined according to the variations of the inner diameter of the sleeve $\left(d_{1}\right)$ and the thickness of the effective swaging zone $(t)$ while fixing the values of the inner diameter of the dice to $16 \mathrm{~mm}$ and the thickness $\left(t_{0}\right)$ of the steel pipe to 5.5 $\mathrm{mm}$. The value of $5.5 \mathrm{~mm}$ for $t_{0}$ has been chosen to increase gradually the pressure in the stress relief zone without occurrence of swaging-induced pressure at the head when the dice with diameter of $16 \mathrm{~mm}$ is compressed during the penetration and to secure a constant pressure in the effective swaging zone. The thickness $t$ of the effective swaging zone is decided to achieve a thickness ratio $\left(t / t_{0}\right)$ ranging between 1.04 and 1.16 . Three different values of 5.5, 6.1 and $6.5 \mathrm{~mm}$ are adopted for the inner diameter of the sleeve. Table 3 arranges the values of the parameters for each analysis model.

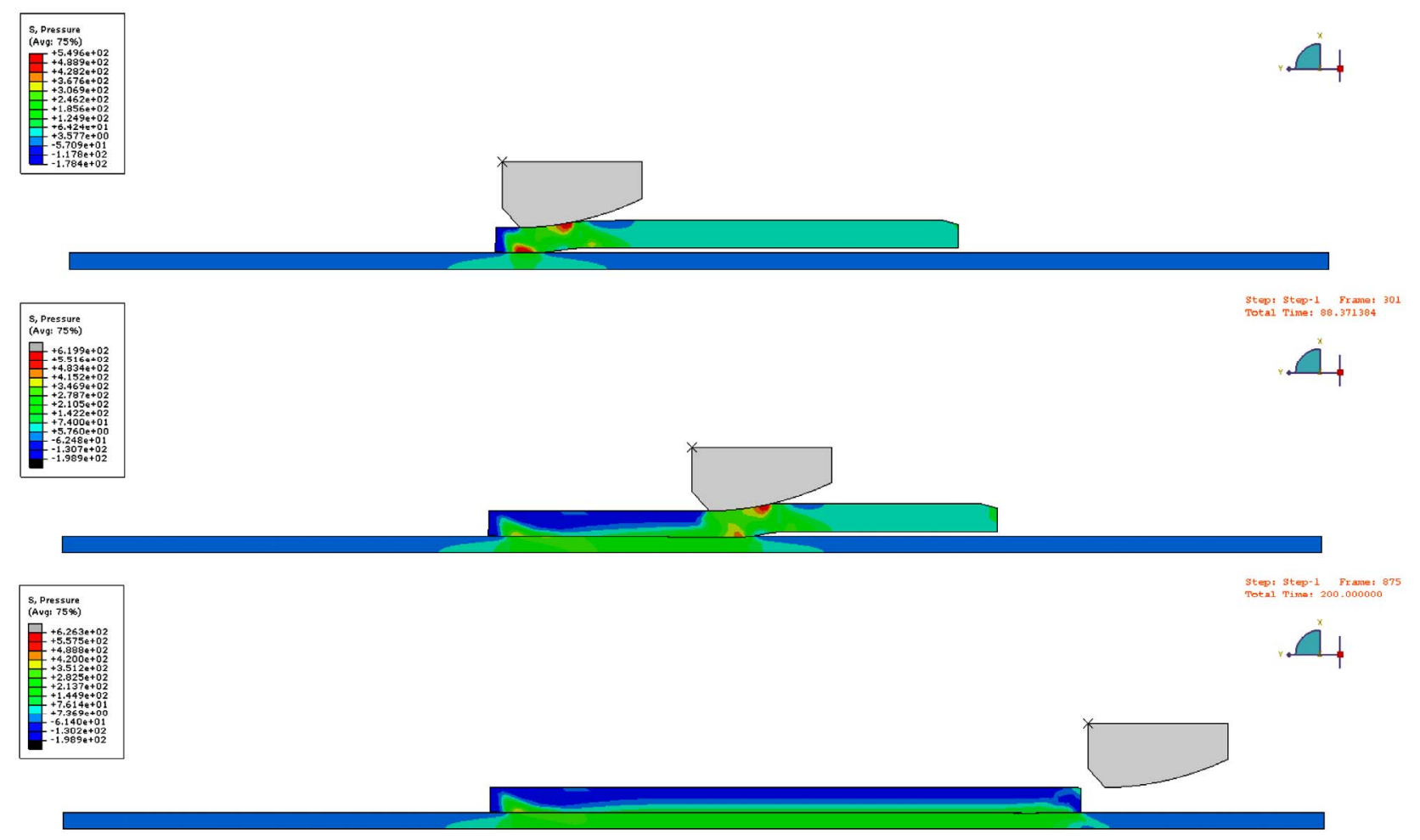

Figure 5. Pressure distribution in cross section during the analysis process. 


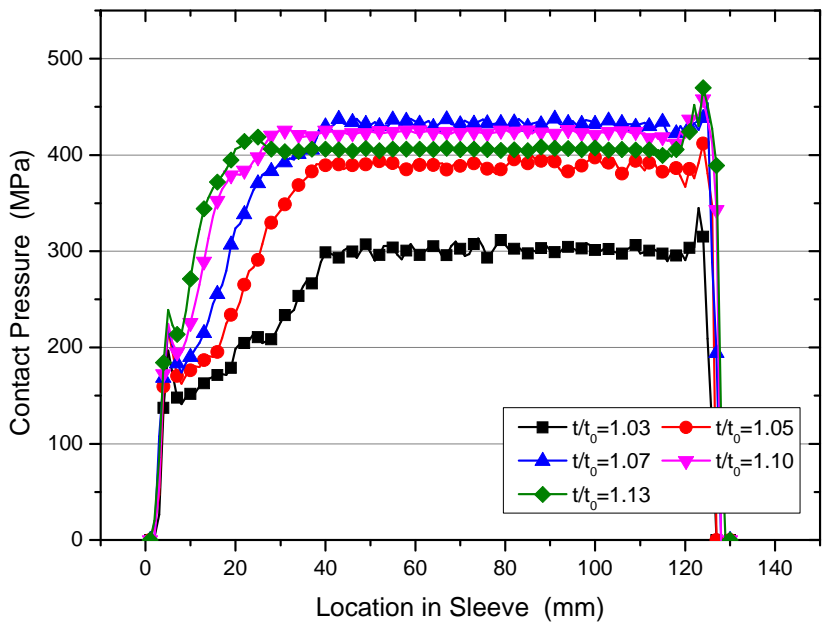

(a)

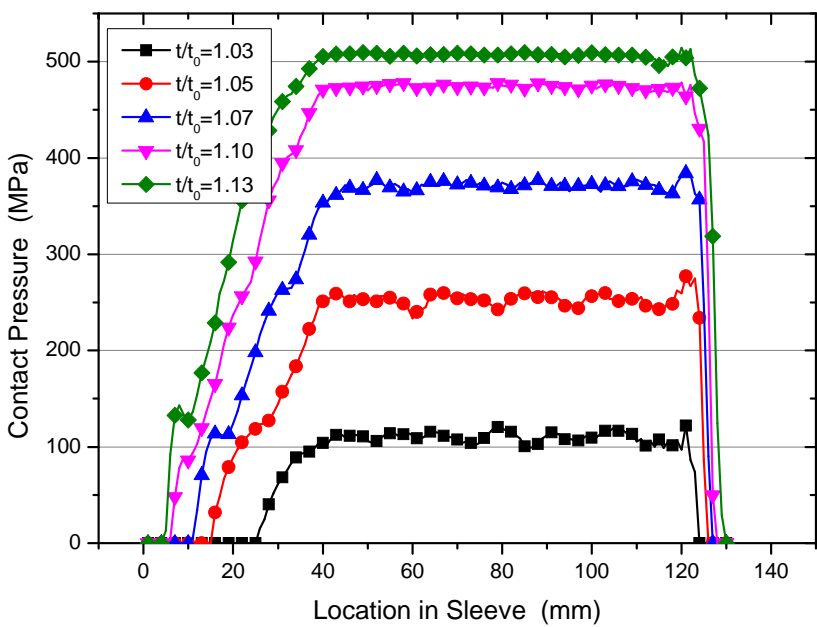

(c)

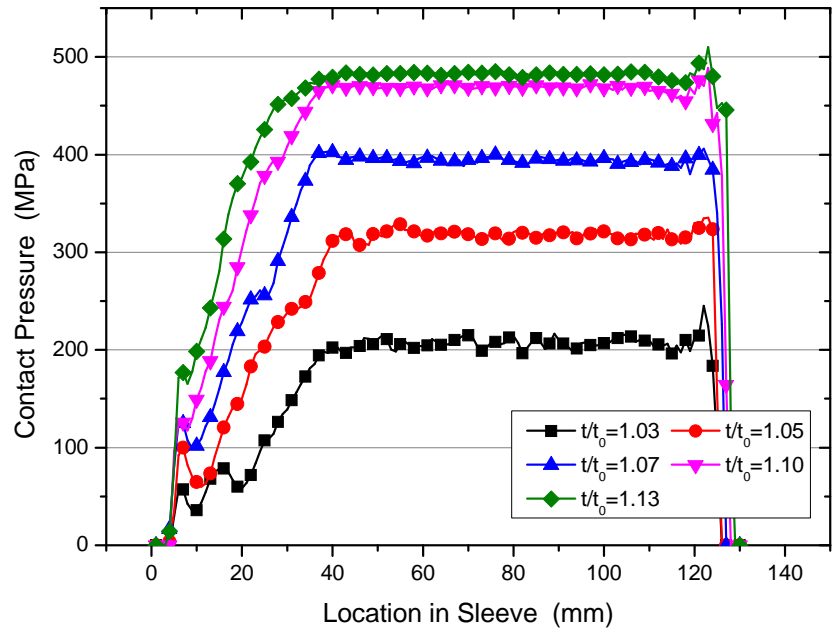

(b)

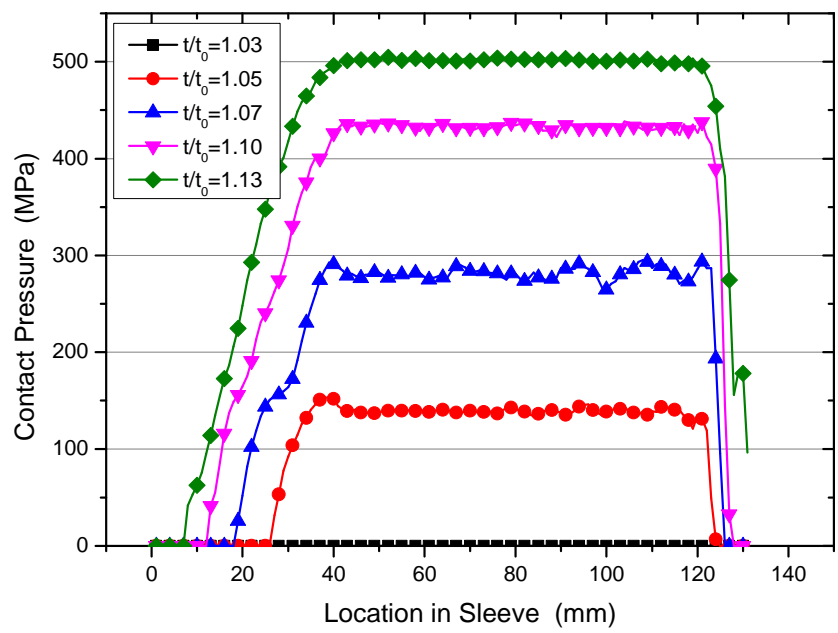

(d)

Figure 6. Pressure distribution in sleeve according to the thickness $t_{0}$ of steel pipe. (a) $t_{0}=4 \mathrm{~mm}$; (b) $t_{0}=5 \mathrm{~mm}$; (c) $t_{0}=6 \mathrm{~mm}$; (d) $t_{0}=7 \mathrm{~mm}$.

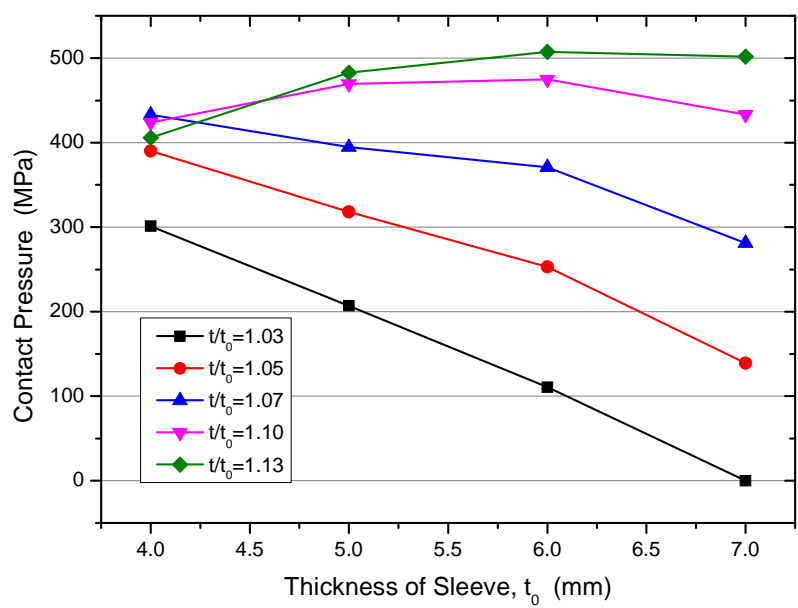

Figure 7. Comparison of mean pressure in sleeve according to $\mathbf{t} / \mathbf{t}_{\mathbf{0}}$.

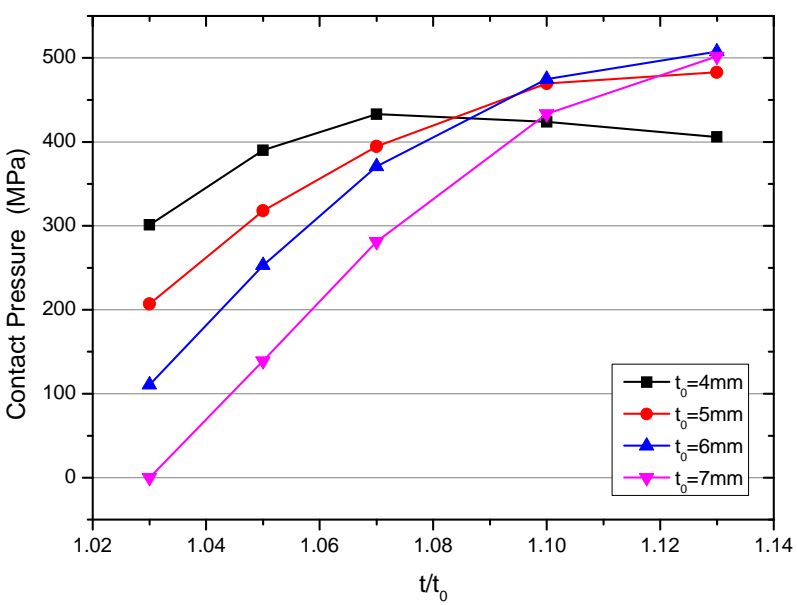

Figure 8. Comparison of mean pressure in sleeve according to the change of the steel pipe thickness $t_{0}$. 
Table 3. Range of parameters in analysis (variations of inner diameter and thickness of sleeve).

\begin{tabular}{|c|c|c|c|c|c|c|c|c|c|}
\hline$t_{0}$ & $t$ & $d_{1}$ & $d_{2}=d_{1}+2 t_{0}(1)$ & $d_{3}=d_{1}+2 t(2)$ & Diameter of dice (3) & (1)/(3) & $(2) /(3)$ & $t / t_{0}$ & Designation of model \\
\hline & 5.7 & & & 16.9 & & & 1.059 & 1.04 & S5-1-1 \\
\hline & 5.8 & & & 17.2 & & & 1.073 & 1.06 & S5-1-2 \\
\hline & 5.9 & & & 17.4 & & & 1.086 & 1.08 & S5-1-3 \\
\hline & 6.1 & 5.5 & 16.5 & 17.6 & & 1.031 & 1.100 & 1.10 & S5-1-4 \\
\hline & 6.2 & & & 17.8 & & & 1.114 & 1.12 & S5-1-5 \\
\hline & 6.3 & & & 18.0 & & & 1.128 & 1.14 & S5-1-6 \\
\hline & 6.4 & & & 18.3 & & & 1.141 & 1.16 & S5-1-7 \\
\hline & 5.7 & & & 17.4 & & & 1.090 & 1.04 & S5-2-1 \\
\hline & 5.8 & & & 17.7 & & & 1.104 & 1.06 & S5-2-2 \\
\hline & 5.9 & & & 17.9 & & & 1.118 & 1.08 & S5-2-3 \\
\hline \multirow[t]{11}{*}{5.50} & 6.1 & 6.0 & 17.0 & 18.1 & 16.0 & 1.063 & 1.131 & 1.10 & S5-2-4 \\
\hline & 6.2 & & & 18.3 & & & 1.145 & 1.12 & S5-2-5 \\
\hline & 6.3 & & & 18.5 & & & 1.159 & 1.14 & S5-2-6 \\
\hline & 6.4 & & & 18.8 & & & 1.173 & 1.16 & S5-2-7 \\
\hline & 5.7 & & & 17.9 & & & 1.121 & 1.04 & S5-3-1 \\
\hline & 5.8 & & & 18.2 & & & 1.135 & 1.06 & S5-3-2 \\
\hline & 5.9 & & & 18.4 & & & 1.149 & 1.08 & S5-3-3 \\
\hline & 6.1 & 6.5 & 17.5 & 18.6 & & 1.094 & 1.163 & 1.10 & S5-3-4 \\
\hline & 6.2 & & & 18.8 & & & 1.176 & 1.12 & S5-3-5 \\
\hline & 6.3 & & & 19.0 & & & 1.190 & 1.14 & S5-3-6 \\
\hline & 6.4 & & & 19.3 & & & 1.204 & 1.16 & S5-3-7 \\
\hline
\end{tabular}

\subsection{Analysis Results}

Figure 9 plots the distribution of the pressure developed in the sleeve according to the thickness ratio $\left(t / t_{0}\right)$. It can be verified that the pressure increases progressively in the stress relief zone to exhibit a constant value in the effective swaging zone.

Figure 10 compares the mean pressure developed in the effective swaging zone. It can be seen that the mean pressure tends to reduce linearly with the decrease of the thickness ratio when the thickness ratio is smaller than 1.1 and, the pressure keeps a constant value higher than approximately $440 \mathrm{MPa}$ even if the thickness ratio increases when this ratio is larger than 1.1. The pressure according to varying inner diameter shows poor variation below about $10 \%$ when the thickness ratio is larger than 1.1 but exhibits increased variation as much as the thickness ratio reduces below 1.1. This difference in the pressure reaches a maximum of $30 \%$ when the thickness ratio is 1.04 .

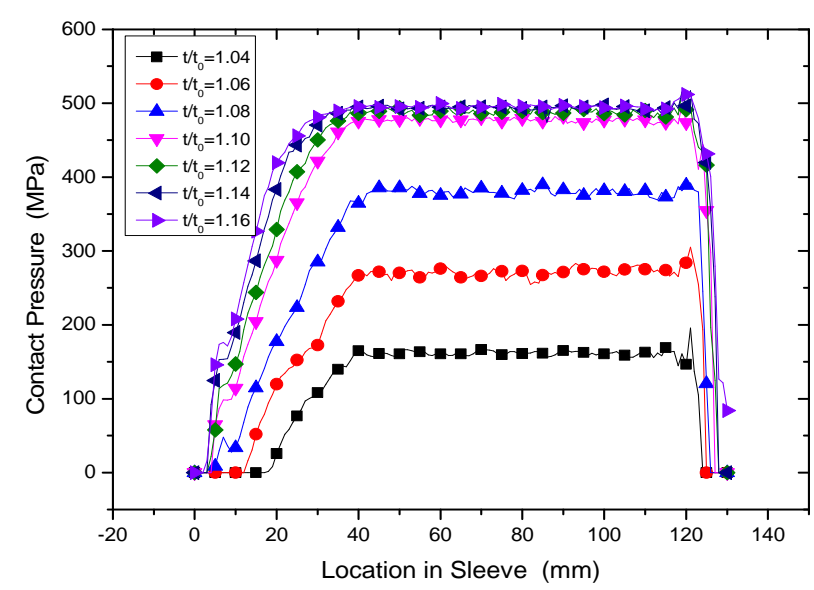

Figure 9. Distribution of pressure in sleeve according to the variation of $t / t_{0}$.

\section{Conclusions}

This paper presented the results of a parametric analysis 


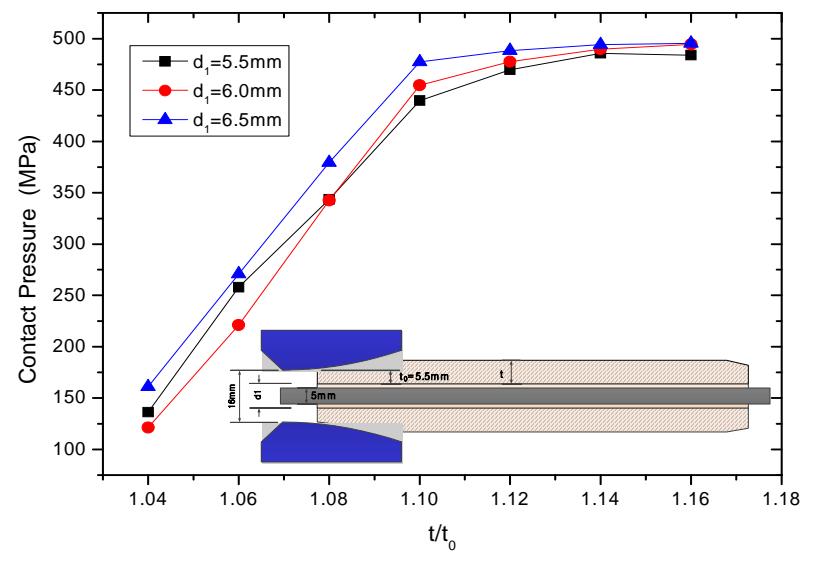

Figure 10. Comparison of mean pressure in sleeve according to the variation of the inner diameter of sleeve.

with the inner diameter $\left(d_{1}\right)$ and the thickness ratio $\left(t / t_{0}\right)$ of the steel pipe sleeve as parameters considering the prestressing reinforcement using a CFRP tendon with diameter of $5 \mathrm{~mm}$. The results enabled to derive the following optimal dimensions of the sleeve achieving the required bond performance without occurrence of slip of the tendon in the sleeve.

(1) A constant pressure of approximately $450 \mathrm{MPa}$ can be obtained in the effective swaging zone when the thickness ratio $\left(t / t_{0}\right)$ of the sleeve is larger than 1.1. Since the pressure which is required to extrude the sleeve increases with larger thickness ratio, the optimal value of the thickness ratio appears to be 1.1 considering the efficiency of construction.

(2) Assuming a thickness ratio $\left(t / t_{0}\right)$ of 1.1 , the variation of the inner diameter of the sleeve is seen to affect the swaging pressure less than $10 \%$. Accordingly, the optimal value of the inner diameter of the sleeve should be $5.5 \mathrm{~mm}$ to reduce the amount of steel and minimize the pressure during the extrusion.

(3) For a dice with diameter of $16 \mathrm{~mm}$ and a sleeve with thicknesses $t_{0}=5.5 \mathrm{~mm}$ and $t=6.1 \mathrm{~mm}$, and inner diameter $d_{1}=5.5 \mathrm{~mm}$, the effective swaging pressure developed in the sleeve takes value of about $440 \mathrm{MPa}$. The corresponding bond force is approximately $104 \mathrm{kN}$ when the length of the effective swaging zone of the sleeve is $80 \mathrm{~mm}$. This value represents about 1.5 times the rupture strength of $70 \mathrm{kN}$ of the CFRP tendon with diameter of $5 \mathrm{~mm}$ and indicates that sufficient bond strength can be secured during prestressing. In order to obtain a bond force comparable to the rupture strength of the CFRP tendon, the length of the effective swaging zone should run around $67.5 \mathrm{~mm}$. The application of a sleeve presenting a longer length of the effective swaging zone will thus achieve sufficient bond performance.

Figure 11 illustrates the optimal dimensions of the swaging type sleeve based upon these requirements and

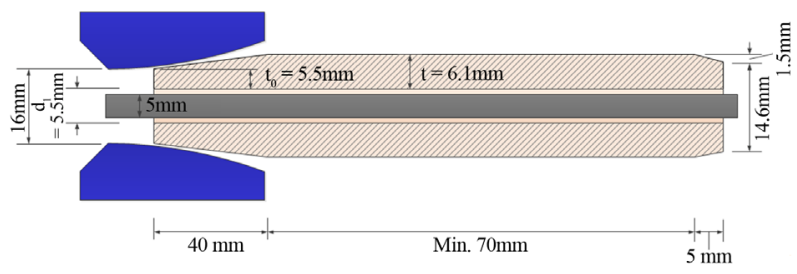

Figure 11. Optimal dimensions of swaging type sleeve for CFRP tendon with diameter of $5 \mathrm{~mm}$.

enables to secure the bond performance of the CFRP tendon with diameter of $5 \mathrm{~mm}$.

It should be noted that the optimal dimensions of the sleeve derived in this study include uncertainties on the actual bond behavior like the assumption of a conservative coefficient of friction between the steel sleeve and the CFRP tendon. The need is thus to verify the bond performance in the future by performing pull out tests based upon the dimensions of the sleeve derived in this study and to examine their site applicability.

\section{Acknowledgements}

This research was supported by grant from Strategic Research Project (Development of Bridge Strengthening Method using Prestressed FRP Composites) funded by Korea Institute of Construction Technology.

\section{REFERENCES}

[1] N. Nordin and B. Talisten, "Concrete Beams Strengthened with Prestressed near Surface Mounted CFRP," Journal of Composites for Construction, Vol. 10, No. 1, 2006, pp. 60-68.

http://dx.doi.org/10.1061/(ASCE)1090-0268(2006)10:1(6 0)

[2] A. Hajihashemi, D. Mostofinejad and M. Azhari, "Investigation of RC Beams Strengthened with Prestressed NSM CFRP Laminates,” Journal of Composites for Construction, Vol. 15, No. 6, 2011, pp. 887-895. http://dx.doi.org/10.1061/(ASCE)CC.1943-5614.0000225

[3] W. T. Jung, Y. H. Park and J. S. Park, “An Experimental Study on Improving Anchor Performance for CFRP Tendons,” American Concrete Institute, Vol. 275, 2011, pp. 1-16.

[4] J. Schön, "Coefficient of Friction for Aluminum in Contact with a Carbon Fiber Epoxy Composite," Tribology International, Vol. 37, No. 5, 2004, pp.395-404. http://dx.doi.org/10.1016/j.triboint.2003.11.008 